\title{
A Study of Pronunciation Problems of English Learners in China
}

\author{
Fachun Zhang \\ Foreign Languages School, Ludong University \\ 186 Hongqizhonglu Road, Yantai 264025, China \\ Tel: 86-535-492-3230_E-mail: timothyzfc95@sina.com \\ Pengpeng Yin \\ Foreign Languages School, Ludong University \\ 186 Hongqizhonglu Road, Yantai 264025, China \\ Tel: 86-535-669-3555 E-mail: crysta10506@sina.com
}

\begin{abstract}
This paper analyzes some frequently occurring problems concerning pronunciation of English learners in China. Factors leading to these problems are interference of Chinese, learners' age, attitude, and their insufficient knowledge of phonology and phonetics systems of the English language, etc.
\end{abstract}

Keywords: Interference of Chinese, Pronunciation, English learner Introduction

\section{Introduction}

Language is a means of communication in everyday life. Common people have little regard the speaking ability as significant as linguists do. They just take it for granted and think that speaking and understanding is as natural as breathing. So many English learners prefer learning "DUMB ENGLISH" to paying attention on studying English pronunciation, the results being that learners are shocked whenever they meet difficulties in oral communication. Among many other factors, the most prominent is phonetics, which, to a large extent, weakens the learner's confidence both in speaking and listening. In the case of some senior students at the university, a reasonable accuracy in the pronunciation of individual sounds should certainly have been achieved, however, many students still fail to attain perfection. Xu Li Hua (1991) pointed out: "The Chinese students are comparatively quiet and shy, which works to their disadvantage in speaking. They are afraid of making mistakes. They feel uncomfortable in their first attempt at speech in English and they are afraid of failure, laughter and ridicule". This comment is very true. Observations that limited pronunciation skills can undermine learner's self-confidence, restrict social interaction, and negatively influence estimations of a speaker's credibility and abilities are not new(Morley,1998).

The ability of speaking English embodies the correctness of pronunciation and intonation and directly affects the appropriate communication in conversation. This paper explores some factors influencing English pronunciation from the objective factors and analyzing two sounds systems by comparing English and Chinese pronunciations, and then provides some practical suggestions for teaching and learning it.

Pronunciation instruction tends to be linked to the instructional method being used. In the grammar-translation method of the past, pronunciation was almost irrelevant and therefore seldom taught. In the audio-lingual method, learners spent hours in the language lab listening to and repeating sounds and sound combinations. It became popular in the 1950s. This involved a systematic presentation of the structures of the second language, moving from the simple to the more complex. This approach was strongly influenced by a belief using of a lot of practice mechanically and repeatedly. At the time, "foreign-language learning is basically a mechanical process of habit formation." (George, 2002).

Nowadays, it would be hard to find a linguist who would agree with the statement, yet versions of the audio-lingual method are still very commonly used in language learning. With the emergences of more holistic, communication methods and approach to ESL instruction, pronunciation is addressed within the context of real communication. Although there are different versions of how to create 'communicative' experiences in the L2 classroom, they are based on a view that the functions of language (i.e. What it is used for) should be emphasized rather than the forms of the 
language (i.e. correct grammatical structure).

\section{Factors Influencing Pronunciation}

There are several factors influencing the pronunciation of the L2 learners. That is, the first language interference by interference of mother language, learner's age, learner's attitude and psychological, prior pronunciation instruction, and the insufficient language knowledge of English phonology and phonetics.

\subsection{Interference of Chinese to English}

Most researchers agree that the learner's first language influences the pronunciation of the target language and is a significant factor in accounting for foreign accents. So called interference or interference from the first language is likely to cause errors in aspiration, stress, and intonation in the target language. Some Chinese students tend to have difficulty with English sounds because they are deeply influenced by similar Chinese sounds. However, they are very different from each other. A particular sound which does not exist in the native language can therefore pose a difficulty for the second language learners to produce or some times to try to substitute those sounds with similar ones in their mother tongue. These sounds include both vowels and consonants. For example, there are no vowels like /æ/, /au/, and $/ \varepsilon ə /$, etc. or no such consonants as $/ \delta /, / \theta /$. Therefore learners have trouble first of all in perceiving these sounds, and consequently try to find nearest equivalents to substitute those new sounds. A typical example will be the substitution of /s/ or /z/ for the English / $/$ /, /ai/ or /e/ for the English /æ/ as in the word 'that'.

A sound does exist in the native language, but the place of articulation and the manner of articulation of the sound in two languages are quite different. The erroneous substitution takes place here as well. For instance, the English $/ \mathrm{r} /$ and / $/$ / are very different from the Chinese /sh/ and $/ \mathrm{r} /$. Therefore it is not surprising when the words 'English', 'pronunciation', 'rose' and 'rise' are uncomfortably heard when they are produced by ESL learners.

A sound does exist in the native language, but not as separate phonemes: that is to say, the learner does not perceive it as a distinct sound that makes difference to meaning. In Chinese the sound /i/ exist, but whether the vowel is long or short does not make any difference in meaning, while the English phonemes /i:/ and /i/ differs a lot in meaning as in the word 'sheep' and 'ship'. The result is that Chinese learners are not naturally aware of the difference in English and Chinese and may not even hear that difference.

On the whole the two problems are more difficult. A totally new sound is often easily perceived as alien, and once you can hear a sound you are well on the way to being able to pronounce it. But if you cannot hear it then you cannot even attempt to pronounce it, and the problem of perception needs to be overcome before any progress can be made.

The combination of different phonemes differs in the two languages. In Chinese morphemes are generally made up of a consonant plus a vowel with no consonants cluster and usually ending with a vowel. Negatively transferring this character of Chinese phonological rules to English, learners would commonly pronounce words 'book' and 'bed' as /bukə/ and /bedə/, and have problems in pronouncing words 'prompt' and 'thousandths'.

Chinese is a syllable-timed language while English is a stress-timed language and therefore they have a great deal of differences in stress and rhythmic patterns. The basis for Chinese rhythm is the number of syllables, and the production of every syllable virtually takes the same amount of time, while the basis for English rhythm is that of stresses and the stressed syllable takes more time to pronounce. With no knowledge of this significant feature, Chinese learners of English often clearly articulate every English syllable and word in speeches. This results in a foreign-sounding accent, and possibly misunderstanding.

Another difference between Chinese and English is that Chinese is a tone language while English is an intonation language. Intonation transfer from the second language learners' L1 to L2 is a natural phenomenon. A number of studies have found that English spoken by different Chinese dialect groups have different accents (Bolton \& Kwok, 1990). The distinctive system of pronunciation and intonation of Chinese as compared to English may cause Chinese to be perceived as rude and inconsiderate. More serious intonation transfer may even affect comprehension.

Chinese learners of English must be aware of this distinction in order to avoid making errors in intonation. Of course utterances in Chinese have intonation as well and the intonation also falls on the ending words. However, every Chinese word has a fixed tone thus the intonation of the whole sentence must be greatly constrained, and the intonation is actually a slight variation on the basis of the word tone. While for English, intonation can mean life and death. Some phoneticians vividly compare vowels and consonants as the body of English and intonation as the spirit of it. Some linguists claimed that the important thing is not what you say but how you say it, thus placing much emphasis on intonation. The knowledge of intonations and the perception of functions of different intonation patterns will facilitate learners' acquisition of the target language phonological system in great measure.

There are many dialects in China, and different local accents will cause trouble in learning English. For example, students from Yunnan province often have trouble in distinguishing / $\mathfrak{a} /$ with /e/ in the words 'bad' and 'bed' and $/ \mathrm{y} /$ from $/ \mathrm{n} /$ in 'thing' and 'thin'. It is often difficult for a Sichuan student to distinguish $/ \mathrm{n} / \mathrm{and} / \mathrm{l} / \mathrm{in}$ words as 'life' and 
'knife'.

\subsubsection{Stress Factor in the Target Language}

Learners make mistakes in the stress of words and rhythm of sentence, unlike many other languages, English requires that one syllable in each word be stressed more than others. The importance of putting the stress on the right syllable in English words cannot be underestimated; putting the stress on the wrong syllable is more likely to make a word unintelligible than is mispronouncing one of its sounds. The result can be certainly attributed to the mother tongue interference. For many students whose pronunciations are especially hard to understand, misplaced syllable stress is one of the main problems. A change in the stress pattern of a word will change its sounds as well. One word that is stressed differently would have different grammatical functions and different meanings. For example, the word 'subject' has the stress on the first syllable when it is a noun, on the second when it is a verb, and this makes a noticeable difference to the sound of the vowels as well as the meanings of the word. English speech rhythm is characterized by tone-units: a word or a group of words, which carries one central stressed syllable (other syllables, if there are any, are lightened) . In English sentences, not all words are given equal emphasis. Key words (usually the words that contain new or important information) are stressed and pronounced more slowly and clearly than other words. Take for example, the question "Are you going to go to Boston?" If the focus of the question is on where the listener will go, the sentence will sound something like "Ya gonna go ta Boston", the word "Boston" will be pronounced clearly with more emphasis. If, in contrast, the emphasis is on who is going, the sentence would sound like "Are you gonna ta Boston?" While students don't necessarily need to learn to reduce the unimportant words in sentence, they should learn to stress key words. Other words should receive less strength since they are only the words used to link the sentence together. However, learners may stress on whatever word of a sentence, without the knowledge of which words should be stressed.

\subsubsection{Intonation Factor in the Target Language}

Intonation, the rises and falls in tone that make the 'tune' of an utterance, is an important aspect of pronunciation of English, often making a difference to meaning or implication (Chen, 1983). Stress, for example, is most commonly indicated not by increased volume but by a slight rise in intonation .

Intonation patterns in English sentences primarily indicate the degree of certainty of an utterance, i.e. whether is a statement, questions, or suggestion. Most questions in rising intonation, however, Wh- questions (who, what, where, when, why, and how) end with falling intonation. It is important for students to learn these patterns not only in order to communicate meaning, but also in order to avoid unwittingly sounding rude or indecisive.

\subsection{Learners' Age}

Children seem to pick up accents very quickly; and the ability to do seems to diminish with age and the knowledge of their native language to a large extent acts as annoying interference while to their second language learning. Meanwhile, Pronunciation is considered to be the most difficult parts of a language for adult learners to master. Why is it that the younger the learner is, the easier it is to learn the foreign language? One important reason is that, younger learners are able to learn the sound system more effectively, while the learning process of adult learners may be more likely to be hindered because of their age.

The debate over the impact of age on language acquisition and specifically pronunciation is varied. Some researchers argue that, after puberty, lateralization (the assigning of linguistic functions to the different brain hemisphere) is completed, and adults' ability to distinguish and produce native-like sounds is more limited. Others refer to the existence of sensitive periods when various aspects of language acquisition occur, or to adults' need to re-adjust existing neural networks to accommodate new sounds. Most researchers, however, agree that adults find pronunciation more difficult than children do and that they probably will not achieve native-like pronunciation. Yet experiences with language learning and the ability to self-monitor, which come with age, can offset these limitations to some degree.

\subsection{Learners' Attitude and Psychological Factors}

Attitude towards the target language learning can influence achievement in pronunciation. It is not common to find that quite a few students resist coordination with teachers in phonetics classes. Sometimes some other students pronounced separate phoneme uncorrected, these students laughed at them. That needs a correct attitude to learn English pronunciation. A number of researchers have claimed that work on pronunciation should need to be tied in with on the individual's value set, attitudes and socio-schemata (Pennington, 1994). Sometimes, motivation for learning can accelerate the learners' attitude formation. Attitude for learning can either support or hinder pronunciation skills development.

Similarly, the way an individual pronunciation has much to do with his or her personality and psychological or emotional state at a given time. Acton (1984) sees "preparing students psychologically as a necessary correlate to improving their pronunciation. Phonology, he says, has both 'inside-out' and 'outside-in' dimension which function in a kind of loop: 'Not only does personality or emotional state show in pronunciation ... but the converse is also true: 
speakers can control their nerves or inner states by speaking properly". This is the basic tenet of successful programs in voice training and public speaking.'

\subsection{Prior Pronunciation Instruction}

Prior experiences with pronunciation instruction may influence learners' success with current efforts. Learners at higher language proficiency levels may have developed habitual, systematic pronunciation errors that must be identified. As we know, the first impression is very important in every occasion. Some students failed to pronounce some words correctly from the beginning. As they become accustomed to their own version of pronunciation, they would be more likely to mis-comprehend when these words are not correctly pronounced. It is also worth of noticing that the most often misunderstood words are those pronounced similarly. Such as, sheep, ship and house, horse etc. So learners must have a good habit of learning correct pronunciation at the beginning.

\section{Presentation of Distinctions between Chinese and English Phonological System}

The contrastive analysis of the target language and learners' native language can greatly facilitate the second language acquisition. It is necessary to make learners know the differences between the two languages and consciously compare the two languages themselves during the learning process.

\subsection{Phonology}

The vast difference in phonology between English and Mandarin gives rise to difficulty in pronunciation of words for Chinese students. The "Common Speech" is a kind of modern Chinese spoken in Northern China. The phonetic system of this modern Chinese is called "Hanyu Pinyin". The phonological system of Mandarin consists of 23 consonant sounds and 36 vowel sounds, while in English there are 24 consonant sounds and 20 vowel sounds. The most distinctive difference between Mandarin and English phonetically is that Mandarin is a tone language and English is an intonation language. In Mandarin, there are 4 different tones for every syllable; the sounds are (1) high level (-), (2) high rising (/), (3) low rising $(\vee)$ or low dipping, and (4) high falling to low ( $\$ ). The majority of words that differ only in tone are quite unrelated. "-fei (fly); fei (fat); fei (bandit); fei (waste, spend)". (from World Book Encyclopedia). In English, sound variation for different words is affected by varying the vowel and consonant sounds. These fundamental differences make it difficult for the Chinese students to master the English sounds. Usually, the Chinese students will use the mono-syllabic sounds with the tone closet the one he hears to code the pronunciation of new words. This results in a typical accent when he reads or speaks, which further discourages him from speaking.

\subsubsection{Differences in Phonemes}

According to the contemporary phonetician A.C.Gimson, there are 44 English phonemes - 20 vowels and 24 consonants, and there are 47 phonemes if $/ \mathrm{tr} /, / \mathrm{dr} /$ and $/ \mathrm{hW} /$ are counted as English consonants .

However, it is hard to determine Chinese phonemes since every Chinese morpheme has a fixed tone. A better way is to consider morphemes with tones as minimal units to contrast meaning in Chinese. According to Modern Dictionary of Chinese, there are 1382 morphemes in mandarin Chinese, while in General Phonetics, Chinese is said to contain 1644 morphemes.

Each of these two languages has its peculiar phonemes. Many English phonemes have equivalents in Chinese, but some English phonemes do not have Chinese counterparts. For example, there are no Chinese counterparts to English vowels $/ \mathrm{i} /, / \mathrm{u} /, / \mathrm{au} /$ and $/ \mathfrak{m} /$ and consonants $/ \mathrm{\delta} /, / \theta /$ and /r/, etc. More example, /b/, /d/and /g/ in English are unaspirated, voiced sound, while in Chinese are unaspirated, voiceless sounds; English /w/ is bilabial but not in Chinese pinyin.

The place of articulation and manner of articulation function are different in Chinese and English. A distinctive feature in English may not distinguish one phoneme from another in Chinese, and vice versa. For instance, each phoneme in 8

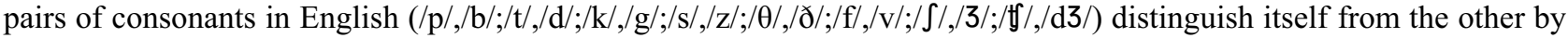
being either voiced or voiceless. That is to say, voiced and voiceless are distinctive features in English. However only $/ \mathrm{sh} /$ and $/ \mathrm{r} /$ in Chinese is a pair of voiceless and voiced sounds, while a most striking distinction between the two is /sh/ is aspirated while $/ \mathrm{r} /$ is unaspirated. Other pairs $(/ \mathrm{p} /, / \mathrm{b} / ; / \mathrm{t} /, / \mathrm{d} / ; / \mathrm{k} /, / \mathrm{g} / ; / \mathrm{z} /, / \mathrm{s} /)$ are all voiceless and they only contrast in aspiration. Therefore aspiration is a distinctive feature in Chinese. That is the reason why Chinese learners of English often neglect the differences between voiced and voiceless sounds in English and native English speakers often overlook the feature of aspiration for it does not contrast meaning therefore non-distinctive.

The position of phonemes and the way of combining them are not the same within the two languages. English consonant clusters do not occur in Chinese as Chinese consonants are always followed by a vowel. Macleish (WWW.melta.org.my/ET/1992/main6.htm/) said: "Consonant clusters present high frequency problems to any speaker who is learning English as a foreign language. This is so because clusters are often combinations of problem sounds; or combinations of familiar consonants does not occur in the native language in clusters." Groups of consonants within one syllable that occur before or after a pause are called "clusters" and those that occur inter-vocalically at syllable or word boundaries are called "sequences"(Bowen, 1983). A clear/l/ usually appear before a vowel in Chinese, but very 
often the vague /1/ occur at the end of a word in English. In Chinese, only $/ \mathrm{n} / \mathrm{and} / \mathrm{y} / \mathrm{can}$ be ending syllables, but in English all consonants can appear at the end of words except $/ \mathrm{h} /, / \mathrm{w} / \mathrm{and} / \mathrm{j} /$.

\subsubsection{Differences between Tone Language and Intonation Language}

Chinese is a language with musical word stress (or tonic word stress). In such a language, prominence is mainly achieved by variations in pitch level, the main acoustic parameter being fundamental frequency. The meaning of the words in Chinese language depends on the pitch levels of their syllables. Every syllable in Chinese has an essential component tone, which is the pitch pattern of the voiced part of the syllable. The pitch and change in pitch of a syllable makes for a difference in meaning. For example, 'mai' (to buy) is the third tone; 'mai' (to sell) is the fourth tone. Both syllables (and, words) have the same initials and vowel sounds, but because their tones are different, their meanings are also different. The same phoneme with four different tones can mean four different things in Chinese. Tones in Chinese can contrast meanings, therefore Chinese is considered as a tone language by modern phoneticians. Tones cannot change the meanings of English phonemes. English utterances must have particular intonation patterns to express different meanings, in this way; English is labeled as an intonation language. However, intonation is not so important for Chinese as for English. It is not uncommon that some English speeches produced by Chinese learners do not sound English; many learners are not able to use intonation to achieve their communicative purposes. Therefore this difference must be clearly pointed out to learners.

\subsubsection{Differences in Juncture}

Chinese and English differ in the juncture between syllables and that between words and consequently differ in their pronunciation. It is very much different between hearing a Chinese speech and an English speech. Using terms borrowed from music, Chinese belongs to staccato, that is to say there are breaks in the continuous flow of speech, while English should belong to legato, and the flow of speech goes smoothly without breaks. The differences of two languages in juncture should be made clear to learners. Chinese speeches sound like tone clusters of piano, and the boundaries between syllables are quite obvious; English speeches sound like gliding tones of violin, and the boundaries between syllables are hard to notice. Another metaphor used to illustrate the difference is that Chinese sentences are like a number of beads strung together, which makes listeners easy to distinguish one phoneme from another; while English sentences are like water streams which flow smoothly though they have ripple on the surface. It is no wonder that one who knows no English at all cannot tell the bounds between syllables and those between words, and the only bound he can perceive is the pauses between two clauses.

It is very likely that Chinese learners make mistakes like stressing every syllable in word or even worse, clearly producing every syllable in a sentence. They are not accustomed to read the sentences smoothly or to use liaisons, thus speak English with a very strong Chinese accent. On that account, differences in juncture require deliberate teaching.

\subsubsection{Phonetic Differences vs. Phonological Differences}

The distinction between phonetics as the general science of speech sounds and phonology as the sounds systems of particular languages has helped to clarify what it is we have to deal with when we learn pronunciation: that is, the physiology of producing speech sounds on the one hand, and on the other, the specific system of distinctive sound features which characterize the target language (Fromkon \& Rodman, 1993). Both disciplines have a contribution to make to pronunciation teaching. But the distinction between them has made it clearer that the learning of new sounds requires relearning movements of the vocal tract and that learning a new pronunciation is to a large extent physiological and learning a new pronunciation is to a large extent physiological and neuromuscular. Is this respect pronunciation teaching is 'more like gymnastics than linguistics' (Streven, 1997). However, because of the fluidity of the speech movements themselves and the different proportions of the vocal tract utilized in different individuals, the movements that create the sounds cannot be described with absolute precision, let alone prescribed in detail. The postures demanded for each segment should be regarded as an idealization of real speech movements, which are made differently by different individuals. What we learn in learning the pronunciation of the target language is a system of relationships among different sounds.

Traditionally, the focus of early stages of pronunciation teaching is the isolated phonemes. The consequence of this focus is that learners still do not pronounce correctly in words or sentences even if they have acquired those phonemes accurately in isolation. In fact, isolated sounds are abstraction, and in actual speech, sounds are produced in a continuous chain in which each individual sound is influenced by proceeding as well as subsequent movements. For example, in English the [-nasal] value of phonemic vowels is changed to [+nasal] phonetically through a spreading process when the vowels occur before nasals.

\section{Conclusion}

In order to learn English well, the second language learners should pay attention of the importance of the English pronunciation learning. 
The factors mentioned above influencing Chinese students pronounce English, which is the first language interference by interference of mother tongue in learning English pronunciation, learners' age, attitude, psychological factor and prior pronunciation instruction and the learners' insufficient knowledge of phonology and phonetics to a large extent affecting the acquisition of the English pronunciation. On the other hand, the presentations of distinctions between Chinese and English phonological systems may raise our awareness of the differences of the two sound systems to avoid errors in pronunciation. Imitation, listening and speaking, Reading aloud are good suggestions for pronunciation improvement of English learners. Certainly, there's a long way for learners of English pronunciation to go.

\section{References}

[Online] Available: WWW.melta.org.my/ET/1992/main6.htm/.

Acton, W. (1984). Changing Fossilized Pronunciation. TESOL Quarterly (1): 69-83.

Bolton, K. \& H. Kwok. (1990). The Dynamics of the Hong Kong Accent: Social Identity and Sociolinguistic Description. Journal of Asian Pacific Communication (1): 72-147.

Bowen, J.D. (1983). Discourse Analysis. London: Cambridge University Press.

Celce-Murcia, M., Brinton, D. \& Goodwin, J. (1996). Teaching Pronunciation: Reference for Teachers of English to Speakers of Other Languages. London: Cambridge University Press.

Fromkon, V. \& A. Rodman. (1993). An Introduction to Language. New York: Harcourt Brac.

George Yule. (2002). The Study of Language( Second edition). Foreign Language Teaching and Research Press.

Li Hua, Xu. (1991). Developing Student's Confidence in Speaking English. Modern English Teacher (3): 74.

Pennington, M.C. (1994). Recent Research in L2 Phonology: Implications for Practice. London: Cambridge University Press.

Streven, P. (1997). New Orientations in the Teaching of English. London: Oxford University Press.

Wenda, Chen. (1983). Strucutres and functions of English Intonation. Shanghai: Shanghai Foreign Language Teaching Press.

Yuhua, Ji. (1994). A New Study of English Pronunciation Teaching. Shandong Foreign Lnaguaes Teahcing (4). 